\title{
Migrating neural crest cells in the trunk of the avian embryo are multipotent
}

\author{
SCOTT E. FRASER ${ }^{1}$ and MARIANNE BRONNER-FRASER ${ }^{2}$ \\ ${ }^{1}$ Division of Biology, Beckman Institute 139-74, California Institute of Technology, Pasadena, CA 91125, USA \\ ${ }^{2}$ Developmental Biology Center, Developmental and Cell Biology, University of Californta, Invine, CA 92717, USA
}

\begin{abstract}
Summary
Trunk neural crest cells migrate extensively and give rise to diverse cell types, including cells of the sensory and autonomic nervous systems. Previously, we demonstrated that many premigratory trunk neural crest cells give rise to descendants with distinct phenotypes in multiple neural crest derivatives. The results are consistent with the idea that neural crest cells are multipotent prior to their emigration from the neural tube and become restricted in phenotype after leaving the neural tube either during their migration or at their sites of localization. Here, we test the developmental potential of migrating trunk neural crest cells by microinjecting a vital dye, lysinated rhodamine dextran (LRD), into individual cells as they migrate through the somite. By two days after injection, the LRD-labelled clones contained from 2 to 67 cells, which were distributed unilaterally in all embryos. Most clones were confined to a single segment, though a few contributed to sympathetic ganglia over two segments. A majority of
\end{abstract}

the clones gave rise to cells in multiple neural crest derivatives. Individual migrating neural crest cells gave rise to both sensory and sympathetic neurons (neurofilament-positive), as well as cells with the morphological characteristics of Schwann cells, and other non-neuronal cells (both neurofilament-negative). Even those clones contributing to only one neural crest derivative often contained both neurofilament-positive and neurofilament-negative cells. Our data demonstrate that migrating trunk neural crest cells can be multipotent, giving rise to cells in multiple neural crest derivatives, and contributing to both neuronal and non-neuronal elements within a given derivative. Thus, restriction of neural crest cell fate must occur relatively late in migration or at the final sites of neural crest cell localization.

Key words: cell lineage, vital dye, microinjection, neural crest, migration, avian embryo.

\section{Introduction}

The neural crest is a cell population that arises during neurulation as the neural folds close to form the neural tube. Neural crest cells migrate away from the neural tube, sometimes traversing considerable distances to form a wide array of derivatives including sensory and autonomic neurons, adrenal chromaffin cells, glia and pigment cells (rev. LeDouarin, 1982). The pathways of neural crest cell migration have been well-documented using a variety of cell markers. In the trunk of the avian embryo, neural crest cells migrate along two predominant pathways after leaving the neural tube. Early migrating cells move ventrally through the rostral half of each somitic sclerotome and toward the dorsal aorta (Rickmann et al. 1985; Bronner-Fraser, 1986) to form dorsal root and sympathetic ganglion cells, as well as adrenomedullary cells. Later migrating cells move beneath the ectoderm where they eventually form pigment cells (Serbedzija et al. 1989).

Although neural crest cells appear morphologically similar at the beginning of their migration, they subsequently give rise to widely varied cell types. The mechanism by which such diversity is generated has been a major focus of study in this system. One possibility is that the choice of phenotypes by neural crest cells is dictated by interactions with their local environment. In the extreme case, the neural crest may be assumed to be a homogeneous population of 'totipotent' cells, each with unrestricted developmental potential. Following migration, the cells differentiate according to instructive cues from their surroundings, acquired either along their migratory pathway or at their final sites of localization. A second possibility is that phenotypic diversity may be inherent to the neural crest cell population. In the extreme case, the neural crest may be assumed to be composed of a heterogeneous mixture of 'predetermined' (unipotent) cells, each fated to become a prescribed cell type. These cells either migrate to their appropriate locations in a directed fashion or migrate randomly, with only those finding their proper sites surviving and/or differen- 
tiating. Of course, a third possibility is that the neural crest represents a combination of multipotent and predetermined cells.

To distinguish between these possibilities, it is necessary to examine the developmental potential of individual neural crest cells within the embryo. An understanding of individual cell lineage is an essential first step for determining the relative importance of the cell's intrinsic program and environmental influences on cell fate. A prospective cell lineage analysis can be accomplished by marking individual cells in situ so that their descendants can be uniquely identified at a later stage of development. We have utilized the technique of intracellular microinjection of the vital fluorescent dye, lysinated rhodamine dextran (LRD; Gimlich and Braun, 1986), for directly labelling individual cells and their progeny in the developing vertebrate nervous system (Wetts and Fraser, 1988; Bronner-Fraser and Fraser, 1988). Because LRD is large and membrane impermeant, the dye is passed from the injected cell only to its progeny by cell division; thus, all labelled cells must be derived from the injected precursor. Observation of the fluorescent dye in living cells immediately after injection permits direct confirmation not only of a cell's position and morphology, but also that only a single cell was labelled.

Previously, we injected lysinated rhodamine dextran into premigratory neural crest cells (Bronner-Fraser and Fraser, 1988) or those just exiting the neural tube (Bronner-Fraser and Fraser, 1989). We found that the majority of trunk neural crest precursors examined in our previous studies gave rise to multiple phenotypes. This indicates that most premigratory and emigrating neural crest cells are multipotent; that is, they are not predetermined to give rise to a prescribed cell type before or as they leave the neural tube (Bronner-Fraser and Fraser, 1988, 1989). Rather, the multipotency suggests that they may respond and differentiate according to environmental cues encountered at later stages, either during migration or at their final resting sites. In order to define better the stages at which restriction of developmental potential may occur, the present study examines the fate of individual neural crest cells injected with lysinated rhodamine dextran after they migrate away from the neural tube and are within or adjacent to the rostral portion of the somite. These migrating neural crest cells are labelled at an older stage than the premigratory neural crest cells within the neural tube examined previously (BronnerFraser and Fraser, 1988, 1989). Here, we demonstrate that many of these migrating neural crest cells give rise to a diverse array of derivatives.

\section{Materials and methods}

\section{Preparation of embryos for injection}

White Leghorn chicken embryos were incubated at $38^{\circ} \mathrm{C}$ until they had 18 to 32 somite pairs, corresponding to stages 13-17 (according to the criteria of Hamburger and Hamilton, 1951). The egg was washed with $70 \%$ ethanol and the embryo was lowered from the shell by withdrawing approximately $1 \mathrm{ml}$ of albumen with a syringe from the wide end of the egg. A window was cut in the shell above the embryo with scissors and a $25 \%$ solution of India Ink (Pelikan, Fount) in culture medium (75\% Minimum Essential Medium, 15\% horse serum, and $10 \%$ embryo extract) was injected underneath the blastoderm to allow better visualization of the embryo. The vitelline membrane of the embryo was deflected above the injection site with a tungsten needle. Following intracellular injection (see below), the window was sealed with cellophane tape (Scotch Magic) and embryos were returned to the incubator for $48 \mathrm{~h}$ prior to fixation. A few embryos were fixed shortly after injection. To minimize phototoxic effects and bleaching of the fluorescent dye, embryos were protected from the light as much as possible during injection, incubation and histological processing.

Intracellular injection of fluorescent lineage tracer dye Windowed eggs were placed onto watch glasses and stabilized with dental wax. After mounting onto the stage of a Zeiss UEM epifluorescence microscope, embryos were viewed with oblique lighting from a fiber optic light source. A $100 \mathrm{mg} \mathrm{ml}^{-1}$ solution of lysinated rhodamine dextran (LRD; Molecular Probes, D-1817, $M_{\mathrm{r}} 10000$ ) was put into the tip of a thinwalled aluminosilicate microelectrode which was then backfilled with $1.2 \mathrm{M} \mathrm{LiCl}$. The microelectrode was mounted on a Huxley-style micromanipulator (Camden Instruments). LRD was injected iontophoretically into a single cell within the rostral half of a somite lying between 6 and 11 somites rostral to the most recently formed somite. Occasionally, injections were made into cells located between the neural tube and somites. Only one injection was made per embryo. During impalement, the membrane potential was continuously monitored to assay the health of the injected cells and to assure that the microelectrode had not drifted to another cell. As an additional assurance that we injected only one cell in the proper location, LRD-labelled cells briefly were observed with epifluorescence immediately after injection. Those that were ambiguous or contained two labelled cells were discarded.

Initially after injection, the dye filled the entire cytoplasm of the injected cell (Fig. 1). With subsequent cell division, the LRD remained cytoplasmic in some progeny but appeared punctate in others. Both morphologies were observed within the same clone and no correlations between the dye distribution and cell type were obvious. The punctate nature of the LRD made it difficult to make exact cell counts. Because only clearly labelled cells were considered, our cell counts may represent underestimates of the number of descendants derived from the single labelled cells.

\section{Histological procedures}

Embryos were removed from the egg and washed in Howard's Ringers (HR) solution. For those allowed to survive for 2 days after injection, embryos were fixed by means of a methanol freeze-substitution procedure as described previously (Bronner-Fraser and Fraser, 1989). Briefly, embryos were rapidly frozen in isopentane cooled in liquid nitrogen for approximately $10 \mathrm{~s}$, and then transferred to cold methanol $\left(-80^{\circ} \mathrm{C}\right.$; $>20 \mathrm{ml} /$ embryo) for three days, followed by a change in methanol and incubation at $-20^{\circ} \mathrm{C}$ for three days, and finally transferred to fresh methanol and incubated at $4^{\circ} \mathrm{C}$ for one day prior to embedding. Embryos were infiltrated with paraplast through a series of solutions in the following sequence, spending approximately $25 \mathrm{~min}$ per solution: from $30 \%$ histosol $/$ methanol, to $70 \%$ histosol/methanol, to two changes of $100 \%$ histosol, to $50 \%$ histosol in paraplast, to three changes of paraplast. Finally, embryos were embedded 
in fresh paraplast. The hardened wax blocks were serially sectioned on a Leitz microtome and sections were mounted on albuminized slides. Sections containing LRD-labelled cells were deparaffinized in histosol, coated with approximately three drops of mineral oil and coverslipped. Sections were viewed through an Olympus Vanox epifluorescence microscope. Data were recorded photographically and onto an OMDR (laser disc video recorder; Panasonic) using a SIT camera and image processor (Imaging Technology 151). After documenting the distribution of LRD-labelled cells, the coverslips were removed and the sections were prepared for immunocytochemistry by rehydration through a graded series of alcohols and, finally, immersion in phosphate buffer (pH 7.5; PB).

A few embryos were fixed shortly after injection to examine the initial distribution and morphology of the LRD-labelled cells. These embryos were fixed in $4 \%$ paraformaldehyde for $1.5 \mathrm{~h}$, rinsed in $\mathrm{PB}$, and placed in $70 \%$ ethanol for a minimum of $20 \mathrm{~min}$. Embryos then were embedded in paraplast by serial dehydration in alcohol, followed by three changes of histosol, three changes of paraplast, and fresh paraplast. Sections were cut and mounted as described above.

\section{Immunocytochemistry}

Sections were stained with a monoclonal antibody against neurofilament protein (kindly provided by Dr Virginia Lee) using hybridoma supernatant, which was diluted up to $1: 500$ in $0.1 \%$ BSA in phosphate-buffered saline (PBS). This antibody (Lee et al. 1988) recognizes a non-phosphorylated epitope on the intermediate neurofilament protein; it stains neuronal processes intensely and cell bodies weakly. Sections were incubated with primary antibody overnight, rinsed in $\mathrm{PB}$, and stained for $1 \mathrm{~h}$ at room temperature with a highly fluorescent goat antibody against mouse Igs (Antibody, Inc., Davis, CA.) diluted 1:300 in 0.1\% BSA in PBS. Slides were coverslipped in glycerol/DABCO and viewed with an Olympus Vanox epifluorescence microscope.

Embryos fixed shortly after injection of LRD were stained with the HNK-1 antibody as previously described (BronnerFraser, 1986). Briefly, sections were deparaffinized and incubated for $2 \mathrm{~h}$ or overnight in supernatant from HNK-1 hybridoma cells. Slides were rinsed in $\mathrm{PB}$ and incubated for $1 \mathrm{~h}$ in FITC-conjugated rabbit antibody against mouse IgM. Slides were washed in $\mathrm{PB}$ and coverslipped in glycerol/ $\mathrm{DABCO}$ prior to viewing.

\section{Analysis of cells with both $L R D$ and neurofilament- immunoreactivity}

In sections of methanol freeze-substituted embryos, no aldehyde fixatives were used to maximize reactivity with the antibody against neurofilament proteins. As a result, much of the LRD washes away after prolonged exposure of the unfixed dextran to aqueous solutions. Therefore, sections that contained LRD-labelled cells were photographed following deparaffinization in histosol and mounting in mineral oil, but prior to antibody staining in aqueous solution; the same sections were photographed again after staining with neurofilament antibodies. Photographic slides of the same sections illustrating the distribution of fluorescent dextran (through a rhodamine filter set) and neurofilament immunoreactivity (through a fluorescein filter set) were used to compare the distribution of LRD-labelled cells and the presence of neurofilament immunoreactivity. Slides were projected and tracings were made of each section using the outlines of tissues and the presence of blood cells and blood vessels as landmarks. Alternatively, simultaneous rhodamine and fluorescein images were superimposed using an image analysis system (Imaging Technologies Series 151; VidIm software; Fraser, Stollberg and Belford, unpublished). LRD-labelled cells that were scored as neurofilament-positive had bright staining in processes and/or weaker staining in the cytoplasm of the soma. Only unambiguously positive or negative cells were scored.

\section{Results}

Neural crest cells migrate away from the dorsal neural tube and invade the rostral half of each somitic sclerotome (Rickmann et al. 1985). In order to label individual migrating neural crest cells, lysinated rhodamine dextran (LRD) was injected iontophoretically into a single cell per embryo within a somite or between the neural tube and somite. The injections were located 6-11 segments above the last-formed somite in host embryos that had 18 to 32 pairs of somites (stages 13-17 according to the criteria of Hamburger and Hamilton, 1951). No obvious correlation was observed between the range of derivatives produced and the exact axial level of injection or the distance from the most recently formed somite; i.e. each axial level produced a similar variety of cells. At the level of the injections, the somites contained two morphologically distinct cell types in addition to migrating neural crest cells: dermomyotomal cells and sclerotomal cells. Although the presence of a single dye-filled cell was confirmed under the epifiuorescence microscope following injection, we were unable to distinguish whether the injected cell was a neural crest cell, a sclerotomal cell or a dermomyotomal cell by visual inspection of intact embryos. The distinct derivatives that arise from each of these cell types assured that no confusion resulted from this uncertainty. By the time of fixation, trunk neural crest cells form adrenomedullary cells, melanoblasts, Schwann cells and neurons and glia of the dorsal root and sympathetic ganglia; in contrast, somite cells form dermis, myotomal cells and mesenchymal cells.

\section{Morphology of LRD-labelled cells fixed soon after injection}

Some embryos were fixed shortly after injection to analyze the morphology of injected cells and to determine the percentage of impalements that labelled neural crest cells. Sections were stained with the HNK-1 antibody to help identify neural crest cells; the HNK-1 antigen appears on the majority $(\sim 70 \%$; Teillet et al. 1987 ) of migrating neural crest cells. Approximately half of the LRD injections were found in neural crest (HNK-1-immunoreactive) cells. The other half were found typically in dermomyotomal cells. Fig. 1 illustrates representative injections of neural crest cells penetrating into the sclerotome (Fig. 1A,B) and immediately adjacent to the neural tube (Fig. 1C). The LRD-labelled neural crest cells are HNK-1 immunoreactive (Fig. 1B) and are morphologically distinct from dermomyotomal cells (Fig. 1D), which are HNK-1 negative (data not shown).

\section{LRD-labelled cells in non-neural crest derivatives} LRD-labelled cells were identified successfully in 28 
embryos fixed two days following injection. Of these, 7 had descendants confined to the myotome, another 3 confined to the sclerotome, and 1 embryo had labelled progeny in both the myotome and the sclerotome. Because these clones did not contribute to neural crest derivatives, they were not considered further in our study. LRD-labelled progeny never were observed within the neural tube after injection of single cells within the somites. Furthermore, no clones contained both neural crest-derived cells and other cell types. Intentional injection of large quantities of LRD into the neural crest cell migratory pathway, without impaling cells, led to no detectable labelling of cells within the embryo, strongly suggesting that cells cannot become labelled with the dye by endocytosis following the death of a labelled neighboring cell.

\section{LRD-labelled cells observed in neural crest derivatives}

17 embryos had LRD-labelled progeny in neural crest derivatives. 8 of the clones were confined to one neural crest derivative, either the dorsal root ganglion, sympathetic ganglion or the ventral root. The remaining 9 clones contained LRD-labelled cells in multiple neural crest derivatives. In the latter embryos, labelled cells were identified in various combinations within the dorsal root ganglion, ventral root, sympathetic ganglion and around the dorsal aorta, where adrenomedullary cells differentiate (Table 1). Thus, about half $(9 / 17)$ of the clones were at least bipotent based on the morphologies and positions of their progeny cells. Furthermore, $18 \%(3 / 17)$ of the clones had LRDlabelled progeny in three or more neural crest derivatives. The percentages of bipotent and multipotent clones obtained from migrating neural crest cell clones are similar to those obtained with injections into single premigratory neural crest cells (Bronner-Fraser and Fraser, 1989).

The progeny of a single LRD-labelled migrating neural crest cell were distributed unilaterally in all

Table 1. Locations of cells derived from clones in embryos fuxed two days after injection of $L R D$ into migrating neural crest cells

\begin{tabular}{lllll}
\hline $\begin{array}{l}\text { No. } \\
\text { embryos }\end{array}$ & DRG & VR & SG & ADRENAL \\
\hline 5 & $\mathrm{X}$ & & & \\
2 & & $\mathrm{X}$ & & \\
1 & $\mathrm{X}$ & $\mathrm{X}$ & & \\
3 & & & $\mathrm{X}$ & $\mathrm{X}$ \\
2 & $\mathrm{X}$ & & $\mathrm{X}$ & \\
1 & $\mathrm{X}$ & $\mathrm{X}$ & $\mathrm{X}$ & $\mathrm{X}$ \\
2 & $\mathrm{X}$ & $\mathrm{X}$ & $\mathrm{X}$ & $\mathrm{X}$ \\
$\mathrm{I}$ & & &
\end{tabular}

An $X$ in a given column signifies the identification of labelled cells in that site.

DRG $=$ dorsal root ganglion.

$\mathrm{VR}=$ ventral root .

$\mathrm{SG}=$ sympathetic ganglia

ADRENAL $=$ adrenomedullary site. cases. In most embryos, clones were confined to a single segment; however, in the two exceptional embryos, labelled cells were observed in two adjacent sympathetic ganglia, together with other derivatives which were restricted to a single segment. Melanocytes were not observed in any of our LRD-labelled clones derived from migrating neural crest cells, although this cell type was found in clones derived from premigratory neural crest cells (Bronner-Fraser and Fraser, 1988, 1989). Perhaps this is not surprising, in that most of our injected cells were located along the ventral pathway through the sclerotome, whereas pigment cell precursors migrate dorsolaterally.

\section{Size and extent of neural crest clones}

Considerable variation was noted in clone size of the progeny derived from individual migrating neural crest cells, with the mean clone size being $23 \pm 21$ cells per clone (mean \pm s.D.). This size is not significantly different from that observed after injection of premigratory neural crest cells $(27 \pm 17$ cells per clone; $0.9>P>0.5$ ). The smallest clones observed contained two cells; these were located in the ventral root in one embryo and in the sympathetic ganglion in another. In contrast, the largest clone contained 67 cells distributed within a dorsal root ganglion and along the ventral root extending into the limb. The frequency distribution of the number of cells per clone is illustrated in Fig. 2. The distribution pattern of clones appears bimodal with peaks around 7 and 43 cells per clone. Those clones contributing to only one neural crest derivative tended to be significantly smaller than those contributing to more than one neural crest derivative (containing $9 \pm 12$ cells compared to $35 \pm 21$ cells per clone, respectively; $P<0.01)$. This trend of larger clones contributing to a wider range of phenotypes is consistent with a stochastic mechanism in the determination of cell type. Assuming that the sites occupied by clonal descendants is determined somewhat randomly, larger clones would be more likely to give rise to multiple derivatives. However, the correlation of large clones containing progeny in more derivatives was not strict: one clone contributing to a single dorsal root ganglion contained 38 cells whereas another clone contributing to both a dorsal root and a sympathetic ganglion contained only 3 cells.

For the 17 embryos that contained labelled neural crest derivatives, the mean rostrocaudal extent was $136 \pm 105$ microns (mean \pm s.D.), with a somewhat broad frequency distribution (Fig. 3). The most extensively spread clones generally contributed to two or more derivatives. The clone with the smallest span was 10 microns in extent and corresponded to the smallest clone size, with 2 cells located in a single sympathetic ganglion. However, a small cell number did not strictly correlate with a limited rostrocaudal extent, since another small clone (containing 3 cells in one sympathetic and one dorsal root ganglion) spanned 130 microns. The two largest clones extended 320 and 330 microns; both contributed labelled cells to two sympathetic ganglia, in addition to other cell types. 

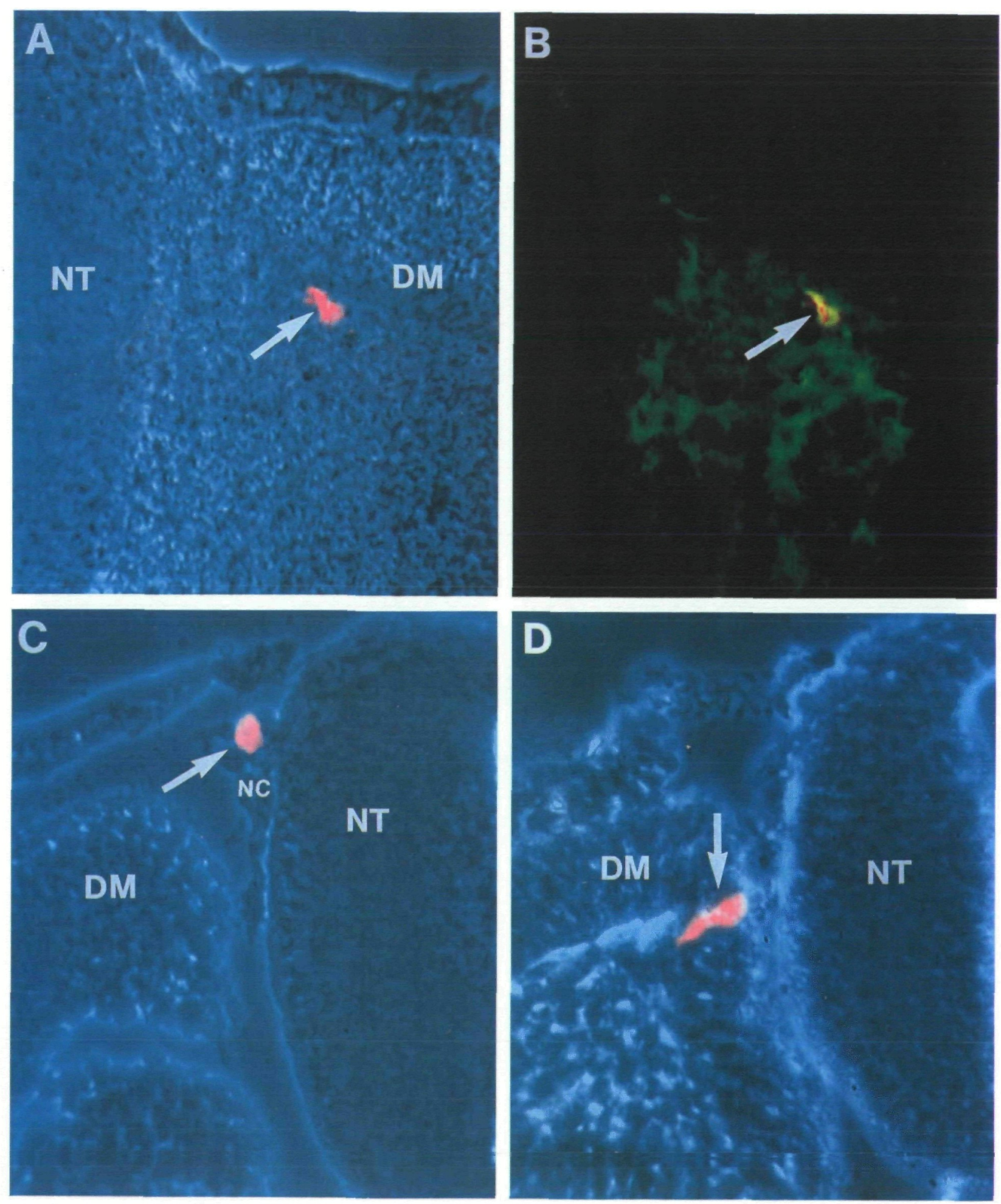

Fig. 1. Positions of lysinated rhodamine dextran (LRD) labelled cells shortly after injection. Each panel shows fluorescence superimposed with bright-field photomicrographs of transverse sections through embryos. (A) A section through an embryo in which a migrating neural crest cell (arrow) within the rostral portion of the sclerotome was labelled with LRD. (B) The same section as A showing superimposed LRD- and HNK-1-reactivity within the sclerotome. The yellow-orange color indicates double labelling with LRD and the HNK-1 antibody, demonstrating that the LRD-labelled cell is HNK-1

immunoreactive. (C) A section through an embryo in which an LRD-labelled cell (arrow) was observed within a stream of migrating neural crest cells (NC) adjacent to the neural tube (NT) and dermomyotome (DM). The labelled cell and its neighbors were faintly HNK-1 immunoreactive (data not shown). (D) A section through an embryo in which a dermomyotomal cell (arrow) was labelled with LRD. This cell was HNK-1 negative (data not shown). Note the distinct epithelial morphology of the dermomyotomal cell. 

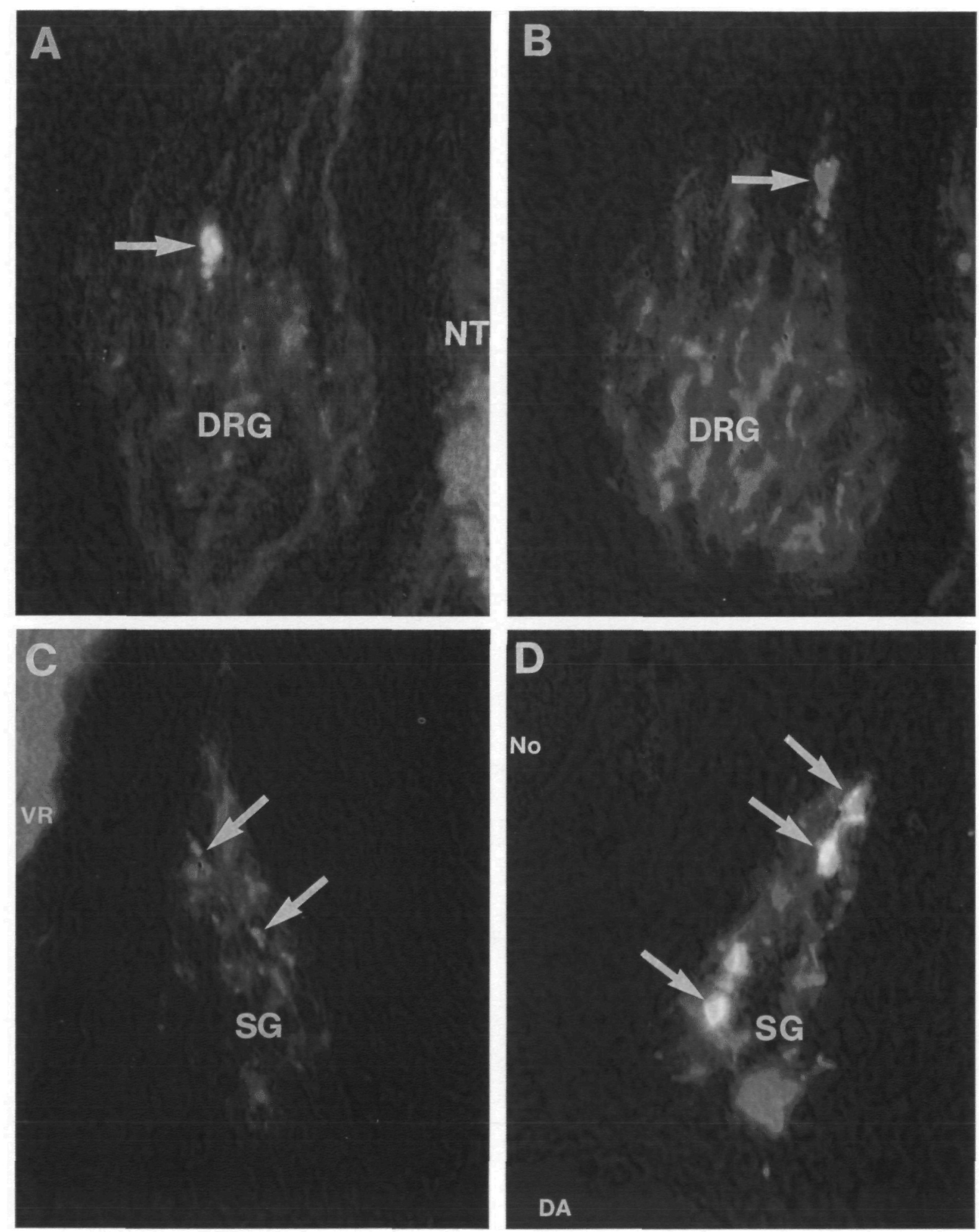

Fig. 4. Neurofilament expression in LRD-labelled descendants. Bright-field image of embryos is shown in blue, the injected lineage tracer (LRD) is shown in red, and staining with an antibody against neurofilament protein is shown in green.

(A-C) Images from an embryo that contained LRD-labelled cells in the dorsal root ganglion (DRG), sympathetic ganglion (SG), and ventral root (VR). (A) An LRD-labelled cell (arrow) in the dorsal root ganglion has bright neurofilament immunoreactivity in its axon. The yellow-orange color of the cells body indicates double labelling with LRD and neurofilament. (B) Another LRD-labelled cell (arrow) within the same ganglion pictured in $A$ is neurofilament-negative and has the typical appearance of a support cell. (C) The sympathetic ganglion of the same embryo pictured in A and B illustrating two neurofilament-negative cells (arrows). This same embryo also contained neurofilament-positive sympathetic neurons. (D) The sympathetic ganglion of another embryo contains numerous cells (arrows) with large cells bodies and axons that are neurofilament positive. This embryo also contained neurofilament-negative cells in the sympathetic ganglion, as well as neurofilament-positive and negative cells around the dorsal aorta. NT, neural tube; VR, ventral root; No, notochord; DA, dorsal aorta. 


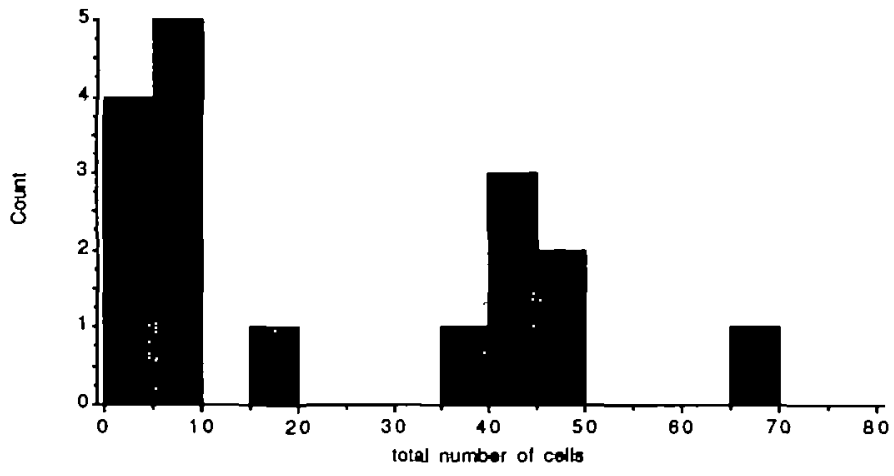

Fig. 2. Frequency histogram illustrating the number of cells per clone derived from a single migrating neural crest cells in 17 embryos. The mean clone size was $23 \pm 21$ (mean \pm standard deviation), with clones contributing to a single derivative versus multiple derivatives having $9 \pm 12$ and $35 \pm 21$ cells per clone, respectively.

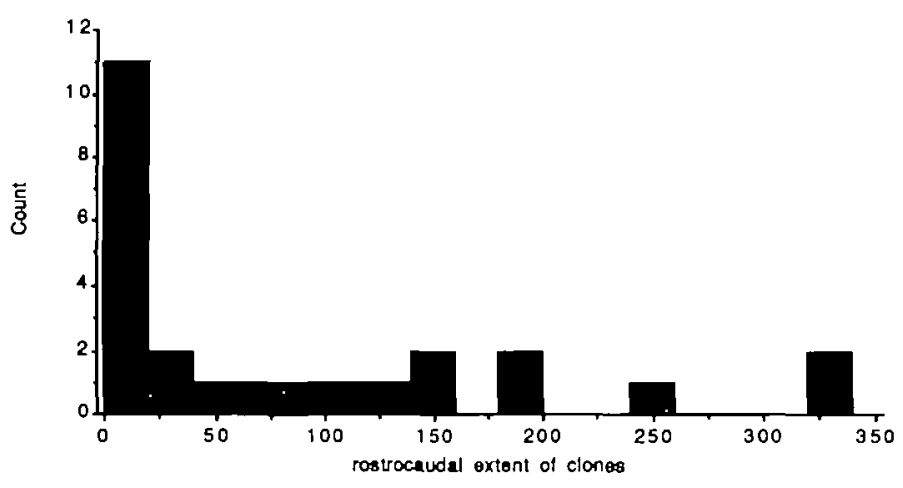

Fig. 3. Frequency histogram illustrating the rostrocaudal extent in microns of clones in 17 embryos, each containing a single migrating neural crest cell clone. The mean rostrocaudal extent was $136 \pm 105$ microns (mean \pm standard deviation).

\section{Neurofilament expression of LRD-labelled cells}

In addition to position, number and distribution, we analyzed the expression of neurofilament protein in the LRD-labelled cells, because it is a marker unique for differentiated neurons. Neural crest cells in the trunk region give rise to three distinct types of neurofilamentpositive cells: dorsal root ganglion neurons (of which there are several classes), sympathetic neurons and precursors to adrenomedullary cells. Based on position, it was possible to distinguish accurately between these three distinct phenotypes. We were not able to discern the different types of neurons within the dorsal root ganglia at the times examined.

We determined whether LRD-labelled cells were neurofilament-immunoreactive by superimposing tracings of images of the same sections viewed under rhodamine (for LRD) and fluorescein (for neurofilament staining) filter sets (see Materials and methods). Of the 17 clones examined, 15 contained labelled cells that could be classified unambiguously as neurofilament-positive or -negative. Only those cells that clearly
Table 2. Distribution of neurofilamentimmunoreactive cells in $L R D$-labelled clones

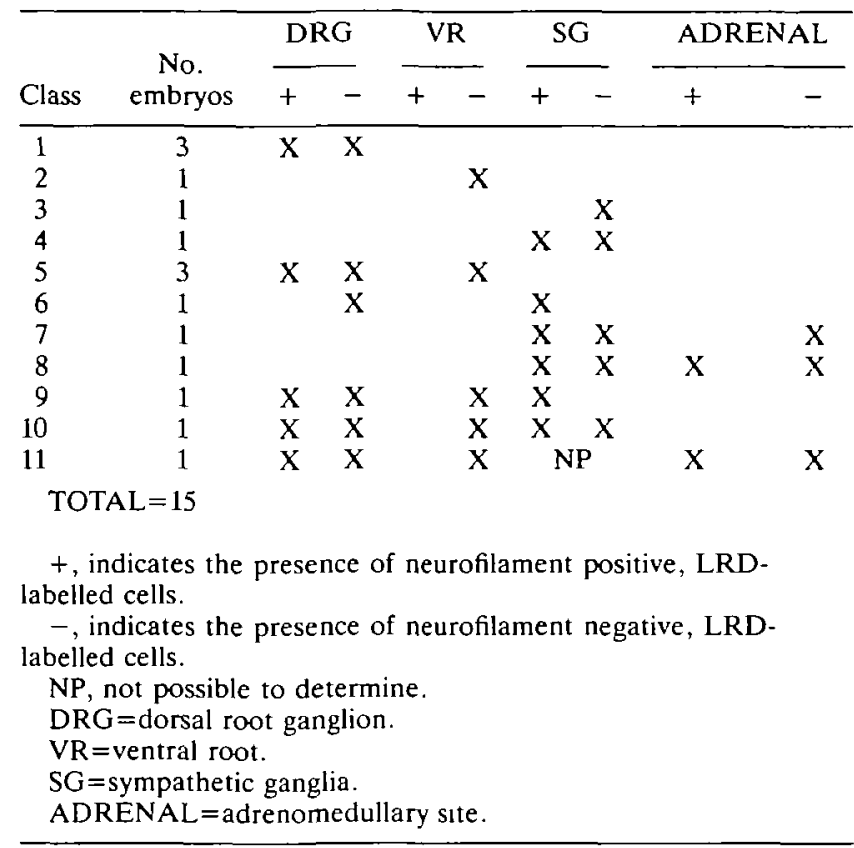

possessed immunoreactivity in their cell bodies or axons were scored as neurofilament-positive, whereas only cells that clearly lacked neurofilament immunoreactivity were scored as neurofilament-negative. Those LRD-labelled cells that could not be unambiguously scored due to close apposition of immunoreactive and non-immunoreactive cells were omitted from further analysis. Table 2 presents, for each embryo, the location of LRD-labelled cells in a given embryo and whether the labelled cells were neurofilament-positive and/or negative.

In six embryos, the clones contributed to only one neural crest derivative (Table 2; Classes 1-4). In those in which the dorsal root ganglion was the only neural crest derivative containing LRD-labelled cells (Table 2; Class $1 ; n=3$ ), both neurofilament-positive and neurofilament-negative cells were observed within the ganglion. In another embryo, the labelled clone consisted of only 2 Schwann cells in the ventral root (Table 2; Class 2), both of which were neurofilamentnegative (as expected of Schwann cells). In the two cases in which only the sympathetic ganglia were labelled (Table 2; Class 3-4), one possessed 2 neurofilament-negative cells; the other contained both neurofilament-positive and neurofilament-negative cells. Thus, even in those cases in which the clone populated only one neural crest derivative, both neurofilament-positive and -negative cells were observed. Although we cannot rule out the possibility that some of the neurofilament negative cells would later differentiate into neurons, the results suggest strongly that the progeny in each clone were not of homogeneous phenotype.

In the remaining clones derived from migrating neural crest cells, progeny were observed in multiple 
neural crest derivatives and exhibited a variety of patterns of neurofilament expression (Table 2; Class $5-11 ; n=9)$. Both neurofilament-positive and -negative cells were observed in all of these clones. For example, three clones (Table 2; Class 6, 9, 10) gave rise to neurons in both the dorsal root (Fig. 4A) and sympathetic ganglia (Fig. 4D). Others (Table 2; Class 7 and 8) gave rise to both neurofilament-positive and -negative sympathoadrenal cells (Figs 4C,D). Some of the neurofilament-negative cells had the appearance of glial or neuronal support cells (Fig. 4B) suggesting that these cells are not merely immature neurons. In the most extreme cases (e.g. Class 11), the clones consisted of an extremely wide variety of cell types, ranging from neuronal and non-neuronal cells in both the dorsal root ganglia and adrenal medulla, to Schwann-like cells along the ventral roots.

\section{Discussion}

After injecting single migrating neural crest cells in the trunk of the avian embryo with a fluorescent vital dye, we found that about half of the resultant clones contributed labelled cells to multiple neural crest derivatives. These cells were injected after they had emigrated from the neural tube and were within or adjacent to the rostral portion of the somite. Previously, we labelled premigratory trunk neural crest cells by injecting them before they emigrated from the neural tube and found that they gave rise to multiple phenotypes (Bronner-Fraser and Fraser, 1988, 1989). The migrating neural crest cells in this study are several hours older than premigratory neural crest cells and differ from premigratory cells in several potentially important ways. First, in contrast to the columnar epithelial arrangement of premigratory neural crest cells, these cells have the distinct morphology of migratory cells. Second, unlike premigratory neural crest cells, they do not give rise to descendants within the neural tube. Third, migrating neural crest cells have exited from and broken contact with the neural tube epithelium, and therefore have a different local environment (i.e. contacting somite cells and numerous extracellular matrix molecules). The progeny of single migrating neural crest cells frequently were found in multiple derivatives. Even those clones in which all of the labelled cells were contained in a single derivative often contained a mixture of neurofilament-positive and -negative cells. This heterogeneity suggests that most neural crest cells are not restricted in developmental potential during their early migration; instead, they have the capacity to develop into a wide variety of both neuronal and non-neuronal phenotypes.

The mean clone size derived from migrating neural crest cells was similar to that observed previously for premigratory neural crest cells (Bronner-Fraser and Fraser, 1989) in embryos fixed two days after injection. Our data suggest that both premigratory and migrating trunk neural crest cells undergo 4-5 cell divisions in $48 \mathrm{~h}$, consistent with the cell cycle times measured in tissue culture (Maxwell, 1976). Migrating neural crest cells were injected in regions that were 6-14 h more mature than those in which premigratory neural crest cells were injected. This is consistent with the possibility that, at most, one cell cycle time has elapsed between the time of injection of migrating compared to premigratory neural crest cells. This difference between premigratory and migrating neural crest confirms the timing for neural crest cell migration deduced from recent fate-mapping experiments (Serbedzija et al. 1989). Clone size ranged widely; interestingly, the smallest clones generally contributed to a single neural crest derivative. This is consistent with the precursors of these small clones being either prespecified and hence smaller, or small and, therefore, likely to be confined to a single derivative. Clones derived from migrating neural crest cells were more spatially restricted than those derived from premigratory cells. Environmental constraints such as population pressure and the presence of permissive and non-permissive regions of migration within the somites (eg. Rickmann et al. 1985) may account for this difference, because they would restrict the rostrocaudal mixing of migrating neural crest cells.

The present results extend previous culture studies in which the developmental potential of individual neural crest cells was assayed by clonal analysis in vitro (Sieber-Blum and Cohen, 1980; Bronner-Fraser et al. 1980; Baroffio et al. 1988; Sieber-Blum, 1989). In these previous experiments, clones derived from cells that migrated away from either the cranial or trunk neural tube were found to give rise to diverse derivatives. By examining the normal descendants of labelled cells in situ, the present experiments rule out the possibility that the multipotentiality observed in previous in vitro experiments could result from artifacts of cell culture; both in vitro and in vivo, many migrating neural crest cells appear to be multipotent.

While these experiments offer definitive proof of the multipotency of some migrating neural crest cells, we cannot rule out the possibility that some neural crest cells are more restricted or even predetermined in their prospective fates. Some of the clones in our study populated single neural crest derivatives; furthermore, in those that populated more than one derivative, it remains possible that some clonally related cells will be eliminated subsequently by cell death. The major period of cell death is after the stages at which embryos were fixed in our study (between embryonic days 4.5 and 9.5 in the dorsal root ganglion; Hamburger and Levi-Montalcini, 1949; Carr and Simpson, 1978). The possibility that cell death later restricts the range of phenotypes from a single precursor is made less likely by the recent experiments of Frank and Sanes (1991). They labelled premigatory neural crest cells within the neural tube with a recombinant retrovirus containing the $l a c Z$ gene. Because the integrated lac $Z$ gene is not diluted by cell division, their analysis could be carried out to a much later stage of development, after the phase of cell death. Their results, which complement our previous results (Bronner-Fraser and Fraser, 1988, 
1989), demonstrate that many neural crest cells give rise to multiple cell types (many types of neurons and well as non-neuronal cells) even within a single dorsal root ganglion. The similarity of their results, obtained after cell death, and our previous results (Bronner-Fraser and Fraser, 1988, 1989) makes it unlikely that sufficient cells are eliminated from the LRD-labelled clones to reduce their multipotency significantly. In their study, a small but significant number of clones gave rise only to neuronal cells within the dorsal root ganglia; we did not observe similar 'unipotent' clones. Thus, it is possible that some of the non-neuronal (neurofilament-negative) cells observed in our clones would have undergone neurogenesis at times after fixation. Most neurons in the dorsal root ganglion are born by our time of fixation but may not yet have differentiated, whereas neurons in the sympathetic ganglia continue to be generated through hatching (Rothman et al. 1978; Rohrer and Thoenen, 1987). It should be noted that the 'unipotent' clones observed by Frank and Sanes (1991) often contained several classes of morphologically distinguishable neurons; therefore, even the precursor to a completely neuronal clone cannot be viewed as totally predetermined.

Some of the clones arising from single migrating neural crest cells were found in only one neural crest derivative, which, some might argue, offers evidence for cells with restricted developmental potential. However, the observation of clonally related cells contained within a single derivative cannot be taken as proof of a 'restriction' in prospective fate, because the range of fates adopted by any one clone is not an accurate reflection of the full potential of the labelled cell. For example, if cell lineage decisions are purely based upon the final location of randomly migrating cells, one would expect, by random assortment, to find some clones in which all cells are contained within a single derivative. The likelihood of such restricted clones increases significantly if there exists an orderly (non-random) pattern of migration as this would limit the intermixing of descendant cells. Interestingly, such is the case for the trunk neural crest, which fills its derivatives in a ventral-to-dorsal order (Serbedzija et al. 1989). Furthermore, the conclusion that a clone is unipotent requires an assurance that all descendant cells always contain the lineage marker. This may not always be the case, since apparently unlabelled cells may be related to labelled cells if injected dye becomes diluted in rapidly dividing cells or if the infected retroviral marker is not expressed in all progeny. In contrast, this is not an issue for the demonstration of multipotency. Significant limitations also apply to other experimental designs for examining predetermination of neural crest cell fate. For example, the existence of monoclonal antibodies that recognize subpopulations of migrating neural crest cells has been taken to indicate a restriction on cell fate (Ciment and Weston, 1982; Payette et al. 1984; Girdlestone and Weston, 1985; Barbu et al.. 1986; Barald, 1982, 1988). However, antigenic diversity cannot be taken to indicate diversity in developmental potential, unless it can be proven that antigenicity at early stages absolutely dictates a prescribed phenotype at later stages in vivo. As a consequence of these and other limitations in present experimental designs, it would be both imprudent and incorrect to conclude that individual neural crest cells are 'restricted' in developmental potential without first perturbing the normal migration pathways or localization of the labelled descendants to challenge their range of prospective fates.

If early migrating neural crest cells are multipotent, when do restrictions in developmental potential take place? A favored model is that interactions between the neural crest cells and their environment guide the selection of phenotype. Most ventrally migrating neural crest cells pass through the somitic milieu; because the entire population is exposed to similar environmental cues, perhaps it is not surprising that these migrating cells are as yet uncommitted to a particular fate. As migration proceeds, different populations of cells are exposed to divergent local environments. Those cells remaining adjacent to the somite and neural tube condense to form dorsal root ganglia, whereas those migrating further ventrally populate the sympathetic ganglia, aortic plexuses and adrenal medulla. Once reaching the level of the dorsal aorta, there is evidence that neural crest-derived cells become partially restricted (Doupe et al. 1985; Anderson and Axel, 1986) to the 'sympathoadrenal' sublineage (precursors to sympathetic neurons, small intensely fluorescent cells, and adrenomedullary cells; Landis and Patterson, 1981). The existence of such partially restricted populations is consistent with the notion that initially multipotent cells become progressively more limited in developmental potential from their interactions during late migratory stages or at their final destinations. Several environmental factors have been suggested to influence phenotypic decisions in the neural crest, including tissues (Cohen, 1972; Norr, 1973), extracellular matrix molecules (Maxwell and Forbes, 1987, 1990; Perris et al. 1988) and growth factors (Birren and Anderson, 1990; Kalcheim et al. 1987). The challenge now becomes to determine which, if any, of these factors are responsible.

Combining the present results with those of earlier studies, the following interpretation emerges. The majority of premigratory and migrating neural crest cells appear to be multipotent in their developmental potential. Intermingled with these multipotent cells, may be minority populations of cells that are more restricted or predetermined in developmental potential. During the final stages of migration or after localization, the multipotent precursors become fully or partially committed. Many factors may impact on the selection of phenotype. For example, timing of emigration from the neural tube may have a major indirect influence because it limits the sites of localization available to the cells (Serbedzija et al. 1989). Thus, the ability of the microinjection technique to label individual cells at specified times and positions may prove critical to an understanding of phenotype selection in the neural crest. 
We thank Kristin Bruk and Mary Flowers for excellent technical assistance and Drs Andres Collazo and Jonathan Ivins for helpful comments on the manuscript. This work was supported by USPHS (HD-25138).

\section{References}

ANderson, D. J. AND AXEL, R. (1986). A bipotential neuroendocrine precursor whose choice of cell fate is determined by NGF and glucocorticoids. Cell 47, 1079-1090

BARALD, K. (1982). Monoclonal antibodies to embryonic neurons. Cell-specific markers for chick cliary ganglion. In Neuronal Development (N. C. Spitzer, ed.) New York: Plenum Publishıng Corp. pp. 101-119.

BARALD, K. (1988). Monoclonal antibodies made to chick mesencephalic neural crest cells and to ciliary ganglion neurons identify a common antigen on the neurons and a neural crest subpopulation. J. Neurosci. Res. 21, 107-118.

Barbu, M., Ziller, C., Rong, P. M. and LeDouarin, N. M.

(1986). Heterogeneity in migrating neural crest cells revealed by a monoclonal antibody. J. Neuroscl. 6, 2215-2225.

Baroffio, A., Dupin, E. and LeDouarin, N. M. (1988). Cloneforming ability and differentiation potential of migratory neural crest cells. Proc, natn. Acad. Scl. U.S.A. 85, 5325-5329.

BirRen, S. J. AND ANDERSON, D. J. (1990). A v-myc-immortalized sympathoadrenal progenitor cell line in which neuronal differentiation is initiated by FGF but not NGF. Neuron 4, 189-201.

Bronner-Fraser, M. (1986). Analysis of the early stages of trunk neural crest migration in avian embryos using the monoclonal antibody HNK-1. Devl Biol. 115, 44-55.

Bronner-Fraser, M. and Fraser, S. (1988). Cell lineage analysis shows multipotentiality of some avıan neural crest cells. Nature 335, 161-164.

Bronner-Fraser, M. and Fraser, S. (1989). Developmental potential of avian trunk neural crest cells in situ. Neuron 3 , $755-766$.

Bronner-Fraser, M. E., Sieber-Blum, M. and Cohen, A. M.

(1980). Clonal analysis of the avian neural crest: Migration and maturation of mixed neural crest clones injected into host chicken embryos. J. comp. Neurol. 193, 423-434.

Carr, V. McM. and Simpson, S. B. (1978). Proliferative and degenerative events in the early development of chick dorsal root ganglia. I. Normal development. J. comp Neurol. 182, $727-740$.

Ciment, G. And Weston, J. A. (1982). Early appearance in neural crest and crest-derived cells of an antigenic determmant present in avian neurons. Devl Biol. 93, 355-367.

CoHEN, A. M. (1972). Factors directing the expression of sympathetic nerve traits in cells of neural crest origin. J. exp. Zool. 179, 167-182.

Doupe, A. J., Landis, S. C. and Patterson, P. H. (1985). Small intensely fluorescent cells in culture: role of glucocorticoids and growth factors in their development and interconversions with other neural crest derivatives. J. Neurosci. 5, 2143-2160.

Frank, E. ANd Sanes, J. R. (1991). Lineage of neurons and glia in chick dorsal root ganglia: analysis in vivo with a recombinant retrovirus. Development 111, 895-908.

Gimlich, R.L. AND Braun, J. (1986). Improved fluorescent compounds for tracing cell lineage. Devl Biol. 109, 509-514.

Girdlestone, J. AND Weston, J. A. (1985). Identification of early neuronal subpopulations in avian neural crest cell cultures. Devl Biol. 109, 274-287.

Hamburger, V. and Hamilton, H. L. (1951). A series of normal stages in the development of the chick embryo. J. Morph. 88, $49-92$
Hamburger, V. and Levi-Montalcini, R. (1949). Proliferation differentiation and degeneration in the spinal ganglia of the chick embryo under normal and experimental conditions. J. exp Zool. 111, 457-501.

Kalcheim, C., Barde, Y.-A., Thoenen, H. and LeDounarin, N. M. (1987). In vivo effect of brain-derived neurotrophic factor on the survival of developing dorsal root ganglion cells. EMBO J. 6, 2871-2873.

Landis, S. C. and Patterson, P. H. (1981). Neural crest cell lineages. Trends Neurosci. 4, 172-175.

LeDouarin, N. M. (1982). The Neural Crest. Cambridge University Press, N.Y.

Lee, V. M.-Y., Otvos, L., Carden, M. J., Hoolosi, M. DietzSCHOLD, B. AND LAZZARINI, R. (1988). Identification of the major multiphosphorylation site in mammalian neurofilaments. Proc, natn. Acad. Sci. U.S.A 85, 1998-2002.

Maxwell, G. D. (1976). Cell cycle changes during neural crest cell differentiation in vitro. Devl Biol. 49, 66-79.

Maxwell, G. D. and Forbes, M. E. (1987). Exogenous basement membrane-like matrix stimulates adrenergic development in avian neural crest cultures. Development 101, 767-776.

Maxwell, G. D. and Forbes, M. E. (1990). The phenotypic response of cultured quail trunk neural crest cells to a reconstituted basement membrane-like matrix is specific. Devl Biol. 141, 233-237.

NorR, S. C. (1973). In vitro analysis of sympathetic neuron differentiation from chick neural crest cells. Devl Biol. 34, 16-38.

Payette, R. F., Bennett, G. S. and Gershon, M. D. (1984) Neurofilament expression in vagal neural crest-derived precursors of enteric neruons. Devl Blol. 105, 273-287.

Perris, R., von Boxberg, Y. And Lofberg, J. (1988). Local embryonic matrices determıne region-specific phenotypes in neural crest cells. Science 241, 86-89.

Rickmann, M., Fawcett, J. W. and Keynes, R. J. (1985). The migration of neural crest cells and the growth of motor axons through the rostral half of the chick somite. J. Embryol. exp. Morph. 90, 437.

Rohrer, H. AND Thoenen, H. (1987). Relationship between differentiation and terminal mitosis: chick sensory and cllary neurons differentiate after terminal mitosis of precursor cells, whereas sympathetic neurons contınue to divide after differentiation. J. Neurosci. 7, 3739-3749.

Rothman, T. P., Gershon, M. D. and Holtzer, H. (1978). The relationship of cell division to the acquisition of adrenergic characteristics by developing sympathetic ganglion cell precursors. Devl Biol. 65, 322-341.

Serbedzua, G., Bronner-Fraser, M. and Fraser, S. E. (1989). Vital dye analysis of the timing and pathways of avian trunk neural crest cell migration. Development 106, 806-816.

Steber-Blum, M. (1989). Commitment of neural crest cells to the sensory neuron lineage. Science 243, 1608-1611.

Sieber-Blum, M. And Cohen, A. M. (1980). Clonal analysis of quail neural crest cells: they are pluripotent and differentiate in vitro in the absence of non-crest cells. Devl Biol. 80, 96-106.

Teillet, A. M., Kalcheim, K. and Le Douarin, N. M. (1987) Formation of the dorsal root ganglia in the avian embryo: segmental origin and migratory behavior of neural crest progenitor cells. Devl Biol. 120, 329-347.

WETTS, R. AND FraSER, S. E. (1988). Multipotent precursor cells can give rise to all major cell types of the frog retina. Science $239,1142-1145$ 